\title{
The robustness of age-related gait adaptations: Can running counterbalance the consequences of ageing?
}

Citation for published version (APA):

Savelberg, H. H. C. M., Verdijk, L. B., Willems, P. J., \& Meijer, K. (2007). The robustness of age-related gait adaptations: Can running counterbalance the consequences of ageing? Gait \& Posture, 25(2), 259266. https://doi.org/10.1016/j.gaitpost.2006.04.006

Document status and date:

Published: 01/01/2007

DOI:

10.1016/j.gaitpost.2006.04.006

Document Version:

Publisher's PDF, also known as Version of record

Document license:

Taverne

Please check the document version of this publication:

- A submitted manuscript is the version of the article upon submission and before peer-review. There can be important differences between the submitted version and the official published version of record.

People interested in the research are advised to contact the author for the final version of the publication, or visit the DOI to the publisher's website.

- The final author version and the galley proof are versions of the publication after peer review.

- The final published version features the final layout of the paper including the volume, issue and page numbers.

Link to publication

\footnotetext{
General rights rights.

- You may freely distribute the URL identifying the publication in the public portal. please follow below link for the End User Agreement:

www.umlib.nl/taverne-license

Take down policy

If you believe that this document breaches copyright please contact us at:

repository@maastrichtuniversity.nl

providing details and we will investigate your claim.
}

Copyright and moral rights for the publications made accessible in the public portal are retained by the authors and/or other copyright owners and it is a condition of accessing publications that users recognise and abide by the legal requirements associated with these

- Users may download and print one copy of any publication from the public portal for the purpose of private study or research.

- You may not further distribute the material or use it for any profit-making activity or commercial gain

If the publication is distributed under the terms of Article $25 \mathrm{fa}$ of the Dutch Copyright Act, indicated by the "Taverne" license above, 


\title{
The robustness of age-related gait adaptations: Can running counterbalance the consequences of ageing?
}

\author{
Hans H.C.M. Savelberg a,*, Lex B. Verdijk ${ }^{a}$, Paul J.B. Willems ${ }^{a}$, Kenneth Meijer ${ }^{a, b}$ \\ ${ }^{a}$ Department of Human Movement Science, Nutrition and Toxicology Research Institute Maastricht (NUTRIM), \\ Faculty of Health Sciences, Universiteit Maastricht, The Netherlands \\ ${ }^{\mathrm{b}}$ Department of Biomedical Engineering, Technische Universiteit Eindhoven, The Netherlands
}

Received 22 August 2005; received in revised form 27 March 2006; accepted 9 April 2006

\begin{abstract}
Previous studies showed age-related redistribution of joint torques from ankle joint plantar flexion to hip joint extension in gait. In the present study it was hypothesized that running can prevent the occurrence of this joint torque redistribution. Four groups of subjects participated in this study (young and elderly both physically active and inactive). All subjects walked at a comfortable, preferred velocity and at an imposed velocity of $1.5 \mathrm{~m} / \mathrm{s}$. Kinematics of lower limb segments and ground reaction forces were assessed. Inverse dynamics method was applied to determine torques around ankle, knee and hip joints. A redistribution of joint torques from plantar flexion to hip joint extension was found to occur in both active and inactive elderly. However, the active elderly had a larger increase of the hip extension torque. By this they are able to maintain the support torque at the level of young subjects. Inactive elderly displayed reduced support torques. It is concluded that the age-related redistribution of joint torques is an important phenomenon. Frequent running does not prevent this shift. Active elderly increase this redistribution to compensate for muscle function reduction.
\end{abstract}

(C) 2006 Elsevier B.V. All rights reserved.

Keywords: Joint torques redistribution; Physical activity; Inverse dynamics; Gait analysis

\section{Introduction}

Ageing is associated with reduced mobility: gait velocity, step length and range of motion of lower limb joints are all decreased [1-4]. This reduced performance capacity is often accompanied by reduced gait stability and increased risk of falling [5-7]. Eventually, reduced mobility can affect activities of daily living, lead to functional dependence and reduced quality of life $[8,9]$. Retardation of muscle function is considered to underlie changes in gait and limitations in mobility. As a result of reduced muscle function gait dynamics is adapted. In the elderly, less work is generated by ankle joint plantar flexors,

\footnotetext{
* Corresponding author at: Department Human Movement Science, Faculty of Health Sciences, Universiteit Maastricht, P.O. Box 616, NL6200 MD Maastricht, The Netherlands. Tel.: +31 43388 1392; fax: +31433670972.

E-mail address: hans.savelberg@bw.unimaas.nl

(H.H.C.M. Savelberg).
}

whereas the contribution of hip extensors is increased $[1,2,10]$. DeVita and Hortobagyi [11] demonstrated that this redistribution of joint torques and powers is independent of walking speed.

Apart from ageing, disuse is considered to contribute to muscle weakness and functional limitations [9]. Muscle tissue responds to physical exercise. In the elderly it has been shown that exercise, including endurance or resistance training, improves muscle function [12-14]. Therefore, it has been suggested that an active life style might counterbalance or even prevent negative consequences of ageing on gait [9].

For an intervention to be effective in maintaining or restoring gait performance, however, improving muscle strength only would not be sufficient. Functional performance is determined by appropriate balance of forces generated by multiple muscles. Therefore, not only the maximum force generated by a muscle is relevant, but also optimal muscle length [15], muscle fibre composition, 
relative strength of agonists and antagonists [16] and neuromuscular coordination [17]. In a recent study we showed that muscles adapt differently to either cycling or running [15]. Furthermore, different muscles in the same muscle group each displayed a specific adaptation pattern. With respect to maintaining gait quality, we hypothesized that running would be the most beneficial intervention. Although the mechanics of the centre of mass in running and walking are different, the muscle function is rather similar. This assumption is based on the similar joint kinematics $[18,19]$, joint moments $[18,20]$ and muscle activation patterns [21]. The major difference in these patterns is that amplitudes of these signals are higher in running. It is known that running requires higher muscle loading than walking [22]. Recently, Karamanidis and Arampatzis [23] found that elderly with running experience have an increased mechanical advantage of knee extensor muscles compared to age-matched inactive subjects. A change in the mechanical advantage of muscles is a major factor in the redistribution of joint moments, as reported by DeVita and Hortobagyi [11].

We hypothesized that, through running, the performance of muscles that are important for walking would be enhanced and that as a consequence gait performance would improve. To test this hypothesis, spatio-temporal, kinematic and kinetic parameters were obtained for four groups of healthy individuals (young and old active runners, young and old inactive people).

\section{Methods}

\subsection{Subjects}

Forty healthy male adults participated: 10 young active adults (YA), 10 young inactive adults (YI), 10 old active adults (OA) and 10 old inactive adults (OI). The active men were athletes who had been running at least twice a week for more than 2 years. The inactive men were non-runners and had not exercised more than once a week for at least 1 year. Level of physical activity was additionally measured through a validated questionnaire [24]. Inclusion criteria for participating in this study were: living independently, performing activities of daily living (ADL) with little or no difficulty and age between 60 and 80 years (elderly); age between 18 and 30 years (young adults); activity score $>9$ (active subjects) and activity score $<5$ (inactive subjects). Exclusion criteria were: disorders or orthopaedic abnormalities of the lower body, neurological or cardiovascular disease, BMI $>28$, medication causing dizziness, history of falls. All subjects gave written informed consent. The study was approved by the university's ethical committee. Young adults were taller than elderly adults $(p=0.000)$ and active subjects were taller than inactive subjects $(p=0.012$; Table 1). Moreover, lower limb length differed significantly between groups (age: $p<0.000$; activity: $p=0.018$; ageactivity interaction: $p=0.05$ ).

\subsection{Experimental procedure}

Subjects were asked to walk down a 12-m walkway with an imbedded force platform. Subjects walked both at their comfortable velocity and at a given velocity that was similar for all participants. For each subject, five trials were collected for two different test situations: comfortable gait velocity and a given gait velocity of $1.5 \mathrm{~m} / \mathrm{s}$. Subjects walked barefoot. Reflective markers were placed on seven anatomical landmarks of the right leg: the head of the fifth metatarsal joint, the calcaneal tuberosity, the lateral maleolus, the head of the fibula, the lateral femoral epicondyle, the greater trochanter and the anterior superior iliac spine (ASIS). It was assumed that errors in positioning of the markers are independent of the group considered. Therefore, it is reasonable that this kind of error will not affect conclusions with respect to differences between the groups. The ground reaction force (GRF) of the right leg during stance was measured at $1000 \mathrm{~Hz}$. Sagittal plane motions of the reflective markers were measured with a 2D, $50 \mathrm{~Hz}$ digital motion analysis system.

Subjects practiced on the walkway to make sure they would step on the force platform without altering their walking pattern. If the foot was not placed properly or if a subject made visually obvious alterations to contact the force platform, the particular trial was discarded.

Table 1

Subject characteristics

\begin{tabular}{lllll}
\hline & Group & & & \\
\cline { 2 - 5 } & Young active (YA) & Young inactive (YI) & Old active (OA) & Old inactive (OI) \\
\hline Age (years) $)^{\mathrm{a}, \mathrm{c}}$ & $23.3(2.3)$ & $22.2(1.9)$ & $65.0(3.4)$ & $70.3(6.0)$ \\
Activity & $14.1(4.2)$ & $4.2(1.1)$ & $11.6(2.4)$ & $4.6(0.6)$ \\
Height $(\mathrm{m})^{\mathrm{a}, \mathrm{b}}$ & $1.89(0.05)$ & $1.83(0.07)$ & $1.75(0.03)$ & $1.72(0.05)$ \\
mass $(\mathrm{kg})$ & $78.1(8.3)$ & $79.1(13.2)$ & $25.7(6.4)$ & $74.9(7.4)$ \\
BMI $\left(\mathrm{kg} / \mathrm{m}^{2}\right)^{\mathrm{a}}$ & $21.8(2.5)$ & $23.4(2.6)$ & $25.6(1.7)$ & $25.3(2.2)$ \\
\hline
\end{tabular}

Values are means (S.D.).

a Significant age effect $(p<0.05)$.

b Significant activity effect $(p<0.05)$.

c Significant age-activity interaction. 


\subsection{Data analysis}

Gait velocity was calculated as the average horizontal velocity of the ASIS marker during a stride. Stride duration was determined as the time between two activation EMGbursts of the gluteus maximus. Stride length was calculated from stride duration and average gait velocity. Cadence was calculated as the number of steps per minute. To cope with leg length differences between subjects a normalized velocity was calculated [25].

The leg was modeled as three rigid segments (foot, lower leg and thigh). Position data of the markers were used to calculate the joint angles of the ankle, knee and hip to determine the position of segments. The filtered (4th order Butterworth) data were differentiated in time to calculate (angular) velocity and accelerations. After transferring the time-scale of the stance phase to a percentile scale, the five trials for each condition were used to calculate average joint angle curves for each participant. From these curves maximal and minimal peak values were assessed to evaluate differences within (comfortable versus given velocity) and between subjects (age and activity).

Based on body mass and segment lengths inertial parameters of segments were estimated [26]. Segment length was determined by the distance between relevant reflective markers. An inverse dynamic approach was used to calculate the net, internal joint torques at the ankle, knee and hip joints during the stance phase. General equations of motion $\left(\sum F=m \times a\right.$ and $\left.\sum M=I \times \alpha\right)$ were applied to the foot, the lower leg and the thigh segment. Plantar flexion, and extension torques at the knee and hip joints were defined positive. Support torque was calculated by summation of the torques at ankle, knee and hip joints [27]. The support torque is considered to represent the overall torque generated in the limb. It gives a quantitative indication of the supporting and propelling muscle effort [11]. From individually averaged joint torque patterns maximal and minimal values were determined. In addition to these characteristics, the value at $35 \%$ of the stance phase was evaluated for the ankle joint pattern. Moreover, joint torque curves were characterized by the surfaces under the curves; these surfaces represent joint impulses.

Joint powers at ankle, knee and hip joints were calculated as the product of joint torque and joint angular velocity. The area under the joint power curves provided the work generated at each joint. Positive work can be interpreted as generation of energy that contributes to propulsion. Negative work indicates dissipation of energy at a joint. At the ankle joint the positive work at the end of the stance phase was calculated. Around the knee joint four phases of subsequent positive and negative work occur; for each of these phases the work was calculated. At the hip joint positive work was generated at the first part of the stance phase. Between 50\% and $75 \%$ of the stance phase a transition from positive to negative work took place. The positive work that was generated at the first halve of the stance phase was calculated.

Previous studies found that ageing affects the ratio of work and joint torques generated at ankle, knee and hip joints [11]. To evaluate this kind of strategy shifts, the mutual ratios between plantar flexion, knee joint extension and hip joint extension work were calculated.

\subsection{Statistical analysis}

Outliers, defined as group mean $\pm>2 \times$ S.D., were excluded from further analysis. Differences in gait characteristics between subjects (age- and activity-effect) and within subjects (comfortable versus given gait velocity) were tested for statistical significance with a repeated measurements analysis of variance. A level of significance of $p<0.05$ was chosen.

\section{Results}

Six subjects were excluded from the entire analysis because either the video- or the force platform-data were not measured accurately (two YA, two YI, one OA and one OI).

\begin{tabular}{|c|c|c|c|c|}
\hline & \multicolumn{4}{|l|}{ Group } \\
\hline & Young active & Young inactive & Old active & Old inactive \\
\hline Gait velocity, comfortable $(\mathrm{m} / \mathrm{s})^{\mathrm{a}, \mathrm{b}}$ & $1.57(0.20)$ & $1.39(0.13)$ & $1.33(0.09)$ & $1.38(0.10)$ \\
\hline Gait velocity, given $(\mathrm{m} / \mathrm{s})^{\mathrm{a}}$ & $1.47(0.06)$ & $1.49(0.07)$ & $1.42(0.04)$ & $1.42(0.05)$ \\
\hline Normalized velocity, comfortable (dimensionless) ${ }^{\mathrm{b}}$ & $0.27(0.06)$ & $0.23(0.04)$ & $0.21(0.03)$ & $0.23(0.03)$ \\
\hline Normalized velocity, given (dimensionless) & $0.24(0.01)$ & $0.23(0.04)$ & $0.24(0.01)$ & $0.24(0.02)$ \\
\hline Step length, comfortable $(\mathrm{m})^{\mathrm{a}}$ & $0.82(0.04)$ & $0.75(0.07)$ & $0.72(0.05)$ & $0.68(0.09)$ \\
\hline Step length, given $(\mathrm{m})^{\mathrm{a}}$ & $0.79(0.02)$ & $0.79(0.06)$ & $0.73(0.04)$ & $0.72(0.04)$ \\
\hline Cadence, comfort. (steps/min) & $126(8.3)$ & $130(8.9)$ & $127(5.0)$ & $119(10.5)$ \\
\hline Cadence, given $(\text { steps } / \mathrm{min})^{\mathrm{a}}$ & $130(3.7)$ & $127(8.9)$ & $123(6.9)$ & $121(6.7)$ \\
\hline
\end{tabular}

\footnotetext{
Values are means (S.D.).

${ }^{a}$ Significant age effect $(p<0.05)$.

b Significant age-activity interaction $(p<0.05)$.
} 


\subsection{Spatio-temporal gait characteristics}

Contrarily to the inactive young adults and both groups of elderly who chose to walk slower in the comfortable gait condition, the young active participants preferred a faster gait $(p=0.033$; Table 2$)$. For both velocity conditions elderly walked slower than young subjects $(p=0.001)$. Activity level did not affect gait velocity. In the comfortable gait condition elderly had a shorter step length than in the given velocity condition ( $p<0.001$; Table 2 ). Cadence was not significantly affected by age. Under the given velocity condition an age effect occurred for cadence. This indicated that both shorter steps and a reduced cadence contributed to a slower gait in elderly in the given velocity condition.

When normalized for lower limb length, age-related difference in gait velocity in the given condition disappeared. In the comfortable condition an age-activity interaction effect remained present; young active participants walked faster than subjects in the other groups.

\subsection{Joint kinematics}

As none of the variables for joint kinematics, torques and powers were significantly affected by gait velocity only results of the given velocity will be presented.

The range of motion of the knee joint decreased with age (young $21.8^{\circ} \pm 3.4^{\circ}$, elderly $19.5^{\circ} \pm 2.3^{\circ} ; p=0.079$ ). The reduced range of motion in the elderly was caused by less knee joint flexion during the initial part of the stance phase $(p=$ $0.055)$. Also the range of motion of the ankle joint depended on age $(p=0.036)$. The range of motion was $14.3^{\circ} \pm 4.0^{\circ}$ for the young adults, $17.2^{\circ} \pm 3.4^{\circ}$ for the elderly. The larger range in the elderly resulted mainly from a non-significantly increased plantar flexion angle at the end of the stance phase.

\subsection{Joint torques}

The support moment was characterized by an M-shaped pattern (Fig. 1a). In the inactive elderly the second peak (interaction age-activity: $p=0.006$ ) and the area beneath the curve (interaction age-activity: $p=0.024$ ) were significantly reduced (Table 3 ).

At the ankle joint (Fig. 1b) a clear difference in the joint torque pattern was found between age groups. In the young adults the plantar flexion torque initially rose to a plateau at $35 \%$ of the stance phase; from about $65 \%$ of the stance phase the torque proceeded to rise to reach a maximal value shortly before toe-off. In the elderly plantar flexion rose gradually from heel strike to toe-off, the plateau-phase was absent. In the elderly, both the plantar flexion torque at $35 \%$ of the stance phase (young: $71.1 \pm 21.7 \mathrm{Nm}$, elderly: $49.1 \pm 12.1 \mathrm{Nm}$; $p=0.001$ ) and the maximal torque (young: $156.0 \pm 22.3 \mathrm{Nm}$; elderly: $133.6 \pm 18.8 \mathrm{Nm} ; \quad p=0.002$ ) were significantly reduced. Moreover, the plantar flexion impulse was larger in the young adults (young: $50.5 \pm 8.5 \mathrm{Nms}$; elderly: $41.6 \pm 5.5 \mathrm{Nms} ; p=0.001)$.
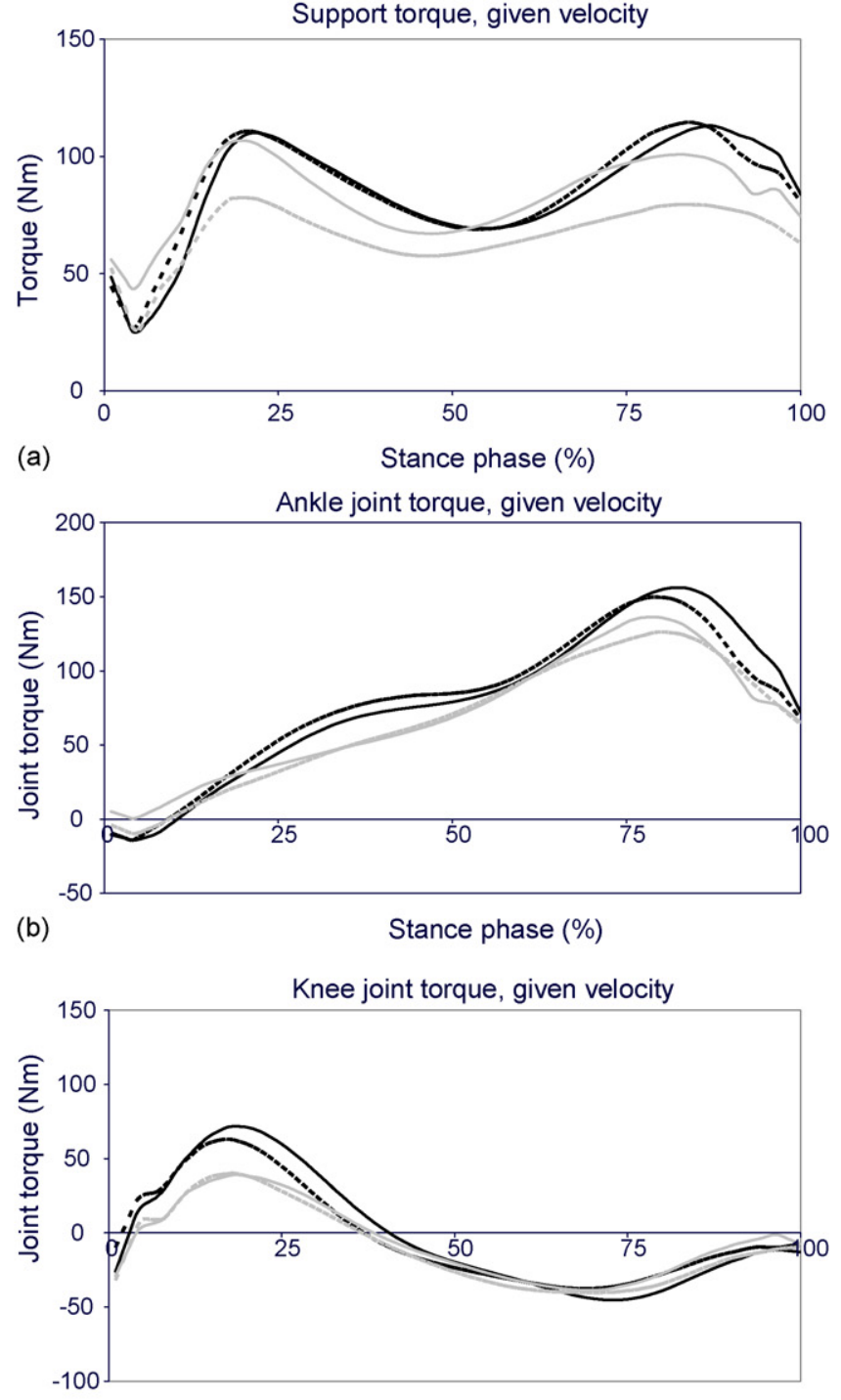

(c)

Stance phase (\%)

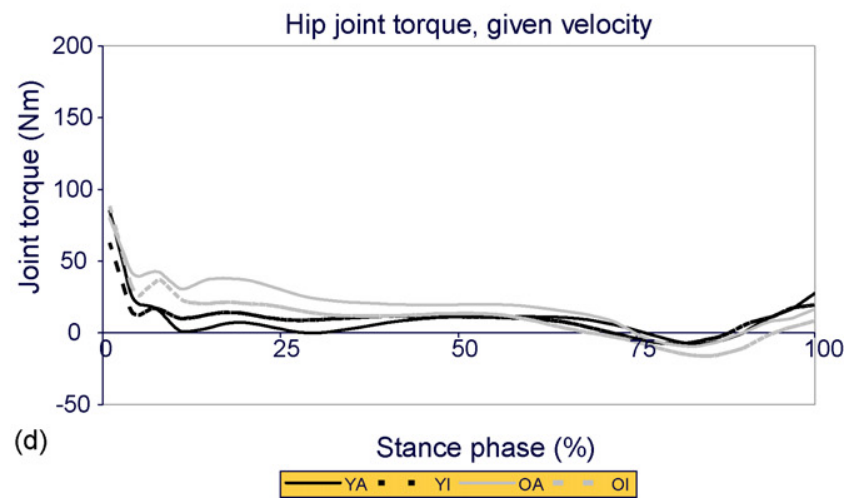

Fig. 1. Joint torques as a function of normalized stance phase for the given velocity: a, support torque; $b$, ankle joint torque; $c$, knee joint torque; d, hip joint torque. Each curve represents average values for the four groups considered (young active (YA) solid black line; young inactive (YI) dotted black line; old active (OA) solid grey line; old inactive (OI) dotted grey line). 
Table 3

Dynamic variables

\begin{tabular}{|c|c|c|c|c|}
\hline & \multicolumn{4}{|l|}{ Groups } \\
\hline & $\overline{\mathrm{YA}}$ & YI & $\mathrm{OA}$ & OI \\
\hline \multicolumn{5}{|l|}{ Ankle joint } \\
\hline $\operatorname{Tmax}^{*}$ & $158.9(23.6)$ & $153.4(22.1)$ & $138.0(18.1)$ & $128.1(19.4)$ \\
\hline $\mathrm{T}_{\mathrm{at}} 35 \% *$ & $67.0(25.0)$ & $74.9(18.8)$ & $48.9(13.7)$ & $49.2(10.7)$ \\
\hline Plantar flexion impulse* & $51.0(8.2)$ & $50.1(9.1)$ & $42.9(6.4)$ & $40.0(3.9)$ \\
\hline $\operatorname{Pmax}^{*}$ & $327.6(71.0)$ & $364.6(95.3)$ & $268.7(82.7)$ & $219.1(82.6)$ \\
\hline Wplant flex ${ }^{*}$ & $21.3(6.4)$ & $27.9(11.6)$ & $19.9(7.7)$ & $18.1(6.0)$ \\
\hline \multicolumn{5}{|l|}{ Knee joint } \\
\hline Tmax.ext. $^{*}$ & $73.0(12.1)$ & $64.7(12.5)$ & $42.1(13.8)$ & $41.2(21.2)$ \\
\hline Tmax.flex & 48.9 (10.7) & $39.3(9.2)$ & $42.9(13.1)$ & 44.4 (14.5) \\
\hline Extensor impulse ${ }^{*}$ & $9.8(1.5)$ & $8.3(2.3)$ & $4.6(2.7)$ & $4.9(3.7)$ \\
\hline Flexor impulse & $10.7(2.2)$ & $10.1(1.3)$ & $8.8(3.2)$ & $10.6(5.3)$ \\
\hline Pmax.ext ${ }^{*}$ & $118.0(26.4)$ & $112.9(22.4)$ & $82.8(27.5)$ & $52.1(27.4)$ \\
\hline Pmax.flex & $69.9(16.7)$ & $64.7(30.1)$ & $61.4(24.2)$ & $64.6(37.6)$ \\
\hline Wext.neg*\$ & $-7.3(1.8)$ & $-8.2(2.5)$ & $-4.7(1.8)$ & $-2.5(1.7)$ \\
\hline Wext.pos & $5.96(1.8)$ & $5.2(2.9)$ & $3.0(0.7)$ & $4.2(3.6)$ \\
\hline Wflex.neg & $-4.4(1.9)$ & $-4.1(1.7)$ & $-2.5(1.8)$ & $-4.2(2.5)$ \\
\hline Wflex.pos & $6.8(1.1)$ & $7.4(1.5)$ & $6.2(4.0)$ & $6.6(3.3)$ \\
\hline \multicolumn{5}{|l|}{ Hip joint } \\
\hline Tmax.ext ${ }^{*}$ & $11.0(5.7)$ & $20.7(11.5)$ & $30.4(7.7)$ & $25.5(14.7)$ \\
\hline Tmax.flex & $15.6(6.2)$ & $9.2(12.4)$ & $15.5(11.2)$ & $19.3(15.7)$ \\
\hline Extensor impulse & $2.7(2.3)$ & $6.0(4.4)$ & $8.7(2.6)$ & $8.0(5.5)$ \\
\hline Flexor impulse & $1.2(0.6)$ & $1.1(1.2)$ & $1.4(1.8)$ & $2.2(2.5)$ \\
\hline Pmax.ext. ${ }^{*}$ & $32.2(30.4)$ & $34.3(16.9)$ & $62.5(17.7)$ & $76.7(59.0)$ \\
\hline Wext ${ }^{*}$ & $3.2(2.1)$ & $9.0(7.8)$ & $13.3(5.1)$ & $11.5(9.1)$ \\
\hline \multicolumn{5}{|l|}{ Support torque } \\
\hline Tpeak1 & $107.7(22.5)$ & $112.5(26.1)$ & $108.9(24.8)$ & $86.2(15.0)$ \\
\hline Tvalley & $60.2(10.9)$ & $66.3(14.1)$ & $63.6(13.4)$ & $55.2(7.1)$ \\
\hline Tpeak $2^{* \$}$ & $106.7(19.7)$ & $117.2(16.7)$ & $102.6(14.0)$ & $80.4(11.3)$ \\
\hline Support impulse ${ }^{* \$}$ & $51.0(10.0)$ & $54.2(8.9)$ & $50.4(8.3)$ & $40.1(3.7)$ \\
\hline \multicolumn{5}{|l|}{ Work ratios } \\
\hline Plant.flex/knee ext. ${ }^{+}$ & $3.6(1.5)$ & $7.5(5.5)$ & $5.5(2.7)$ & $7.8(5.9)$ \\
\hline Plant.flex/hip ext. & $7.5(3.4)$ & $5.0(4.9)$ & $1.5(0.8)$ & $2.2(1.9)$ \\
\hline Knee ext./hip ext.* & $1.6(0.7)$ & $1.1(1.4)$ & $0.4(0.4)$ & $0.4(0.4)$ \\
\hline
\end{tabular}

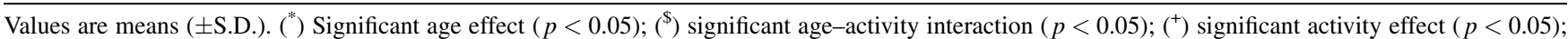
Abbreviations: Tmax: maximal joint torque during the stance phase, an extension '.ext' or '.flex' refers to a maximal extending or flexing joint torque, respectively; Tat 35\%: joint torque at 35\% of the stance phase; Tpeak1, Tvalley and Tpeak2: the support torque at the first peak, the valley and the second peak; Pmax: maximal joint power during the stance phase, an extension '.ext' or 'fflex' refers to a maximal extending or flexing joint power, respectively; W: work generated or dissipated at a joint, extensions 'plant flex', 'ext.neg', 'ext.pos', 'flex.neg' and 'flex.pos' refer to work generated by plantar flexors, and negative or positive work by extensors or flexors, respectively.

The knee joint extension torque was significantly decreased in the elderly (young: $68.8 \pm 12.6 \mathrm{Nm}$; elderly: $41.7 \pm 17.1 \mathrm{Nm} ; p<0.001$; Fig. 1c). Also the extension impulse was significantly larger in the young adults (young: $9.0 \pm 2.0 \mathrm{Nms}$; elderly: $4.7 \pm 3.1 \mathrm{Nms} ; p<0.001$ ). Knee joint flexion torques did not differ between groups.

Elderly subjects had increased hip joint extension torques (young: $16.2 \pm 10.3 \mathrm{Nm}$; elderly: $27.9 \pm 11.6 \mathrm{Nm} ; p=$ 0.004; Fig. 1d). Also the extension impulse was larger in the elderly (young: $4.4 \pm 3.9 \mathrm{Nms}$; elderly: $8.3 \pm 4.2 \mathrm{Nms}$; $p=0.010)$.

\subsection{Joint powers}

The maximal power generated by the plantar flexors at the end of the stance phase decreased significantly with ageing (young: $347.1 \pm 84.5 \mathrm{~W}$; elderly: $246.7 \pm 84.1 \mathrm{~W}$; $p<0.001$; Fig. 2a). This reduction was reflected in the work generated by the plantar flexors (young: $24.8 \pm 9.9 \mathrm{~J}$; elderly: $19.1 \pm 6.9 \mathrm{~J} ; p=0.052$ ).

The pattern of the power generated and absorbed at the knee joint was characterized by four phases (Fig. 2b). During stance negative work was initially generated by the knee joint extensors, but subsequently positive work was produced. Negative work depended on age (young: $7.7 \pm 2.2 \mathrm{~J}$; elderly: $3.6 \pm 2.0 \mathrm{~J} p<0.001$ ). Moreover, in the elderly an effect of activity occurred: the inactive elder participants generated less work than the active elderly $(p=0.037)$. As the positive work generated by the extensors did not differ between groups, the ratio of negative and positive work produced by the knee extensors increased with age $(p=0.005)$, and differed between both groups of 


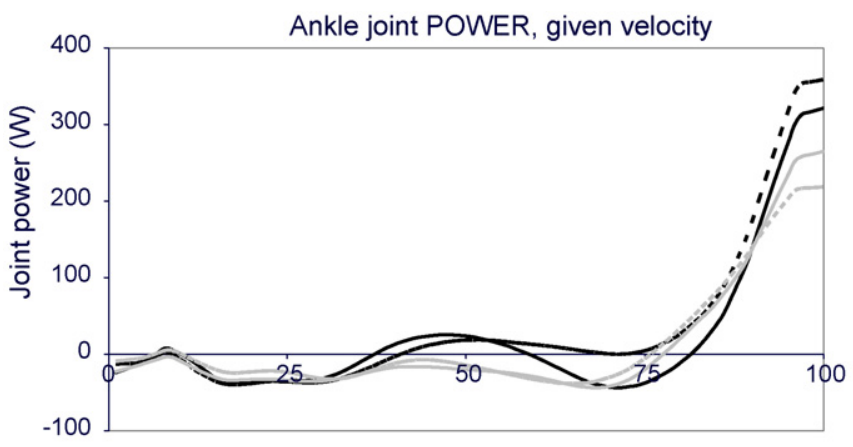

(a) Stance phase (\%)

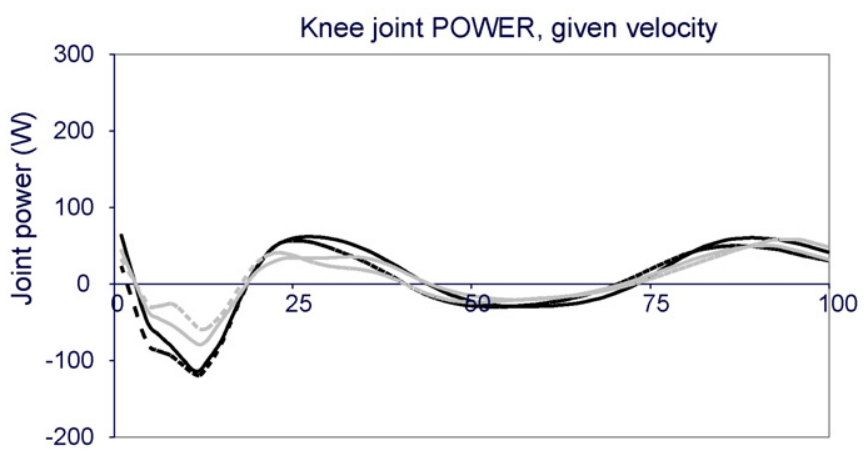

(b)

Stance phase (\%)

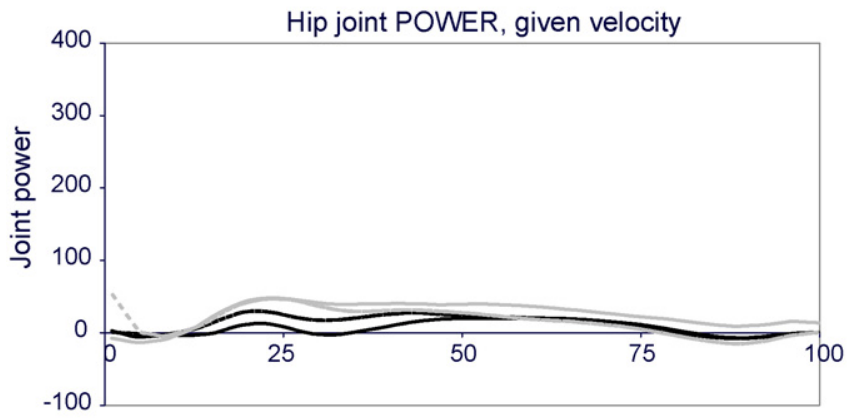

(c)

Stance phase(\%)

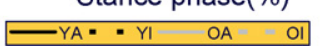

Fig. 2. Joint power as a function of normalized stance phase for the given velocity: a, ankle joint power; b, knee joint power; c, hip joint power. Each curve represents average values for the four groups considered (young active (YA) solid black line; young inactive (YI) dotted black line; old active (OA) solid grey line; old inactive (OI) dotted grey line).

elderly. In the inactive elderly the negative work dissipated by the extensors was less than the work subsequently generated. In the other groups negative and positive work of the knee extensors were similar. During the second half of the stance phase a similar pattern of negative work followed by positive work occurred for the knee flexors, in these phases no differences between groups occurred.

Elderly generated a significantly larger maximal hip joint power than young adults (young: $33.3 \pm 23.7 \mathrm{~W}$; elderly: $69.2 \pm 41.6 \mathrm{~W} ; p=0.009$; Fig. $2 \mathrm{c})$. Due to this the work produced by the hip extensors increased with age (young: $6.3 \pm 6.4 \mathrm{~J}$; elderly: $12.4 \pm 7.2 \mathrm{~J} ; p=0.015$ ).

The distribution of total work over ankle, knee and hip varied with age. In young subjects the plantar flexion work was on the average more than six times the hip joint extension work. In elderly this ratio was reduced to less than two $(p=0.001)$. For the distribution of knee and hip joint extension work a similar age-related shift towards increased contribution of hip extension with ageing occurred $(p=0.012)$. The ratio of knee extension and plantar flexion work changed with activity $(p=0.053)$. In the inactive participants the contribution of knee extension work was reduced relative to plantar flexion.

\section{Discussion}

Two central paradigms in training are (a) that it should be specific and (b) that it should be intense enough to trigger adaptation. The design of this study was based on these 
paradigms, assuming that running is an appropriate intervention to prevent age-related gait adaptations. It was evaluated whether running in particular and physical activity in general prevented the occurrence of age-related gait adaptations.

Several aspects of walking were evaluated: self-selected gait velocity, joint angle kinematics and joint dynamics. It was found that the young active adults choose a faster gait than all other participants. So for gait velocity the conclusion would be that in young subjects running was associated with different performance in walking. Joint kinematics differed between young and older subjects. This was reflected in reduced ankle and knee range of motion in the elderly. Joint dynamics were influenced by both age and activity.

Statistical analysis revealed that, at each joint, several variables representing aspects of the torque or power curves were significantly affected by ageing. A few variables were influenced by the subjects' level of physical activity. This suggests two things. Firstly, the age-related gait adaptations are significant. Secondly, running leads to modest effects on gait performance.

The support torque was one of the variables significantly affected by activity in the elderly. For the active elderly this curve was similar to that of young participants; the inactive elderly had a reduced second peak and a smaller area beneath the curve. It is striking that this composite torque differed significantly depending on level of activity whereas the underlying torques did not. There was a tendency for the underlying torques to difffer between active and inactive elderly. Comparing ankle and hip joint torques at the end of the stance phase provides evidence for this. Plantar flexion showed a tendency towards reduction with ageing and inactivity during the last part of stance ( 75-100\%). Simultaneously, the hip joint torque was lower for the inactive elderly than for the active elderly. Both these variables were not significantly different between both groups of elderly. However, as the trends in both torques are in the same direction, summation resulted in an increased and significant difference in the second peak of the support torques between groups. Similarly, for the first peak of the support torque a difference appears between the two elderly groups by cancellation of effects. During the initial stance phase a significant age-related reduction of about $30 \mathrm{Nm}$ of the knee extensor torque is seen. In the curves of the support torque this reduction reappears for the inactive elderly, but not for the active elderly. For the active elderly, the reduction of the knee joint torque was (partially) compensated by a simultaneous rise of the hip extension torque. As a consequence, the area beneath the support torque curve is not reduced in the active elderly, but is negatively affected in the inactive elderly. Therefore, it is suggested that significant differences in composite variables represent underlying differences in joint torques.

To characterize gait, it can be stated that stance consists of an impact and a propulsion phase. During impact the forward velocity decreases, in the propulsion phase velocity increases.
At impact, extensor torques at knee and hip joint are generated; the propulsion phase is associated with plantar flexion and knee flexion torques. DeVita and Hortobagyi [11] reported a redistribution of plantar flexion to hip extension torques in elderly. In this study the ankle-to-hip shift of joint torques and powers in elderly was demonstrated. However, the idea that active elderly compensate the reduced capacity of the plantar flexors and knee extensors by an additional recruitment of hip joint extensors would indicate that active elderly cope differently with this age-related joint torque redistribution. In this way active elderly maintain the support torque pattern similar to that of young adults. The exact mechanism by which increased hip joint extensor torques in the first half of the stance phase allow active elderly to compensate for reduced torques at knee and ankle joint is not clear.

DeVita and Hortobagyi [11] hypothesized that the redistribution of joint torques resulted from alterations in motor function and pattern. The finding that active elderly compensate for age-induced changes by increasing the contribution of hip extensors would support this hypothesis. It would be interesting to see whether active elderly have increased hip joint extensor strength or manage the gait adaptation by changed neuromuscular coordination. In a previous study [16] we showed that the balance between knee joint extensors and knee joint flexors, which are to a larger extend also hip joint extensors, was affected. In that study the interaction of ageing and physical activity on muscle function was not considered. Karamanidis and Arampatzis [23] found that the properties of knee extensors and plantar flexor muscles were associated with ageing, but not with running experience. To understand whether structural adaptations or changed neuromuscular control are the main site of adaptation, the dependence of muscle strength on age and activity should be considered in future research. This knowledge would contribute to understanding how the gait pattern of elderly subjects could be most efficiently improved.

The current study was cross-sectional, therefore, it cannot be safely concluded whether the differences found between groups were the result of a different lifestyle or ageing. However, the differences found would offer the basis for longitudinal studies to be designed. In accordance with a previous study [11], we showed that ageing is associated with an ankle-to-hip torque shift. Exciting new facts are that (1) this adaptation does not seem to be susceptible to physical activity, i.e. frequent running and that (2) in active elderly subjects an adaptation associated to running was found, which amplified the ankle-to-hip shift, rather than counterbalancing it. In a similarly designed study on running performance [23] comparable results were found. In that study, major differences occurred between young and elderly adults.

The results of the present study raise the question whether improvements in gait performance in elderly could be obtained by enhancing the function of hip extensors rather than by training plantar flexor muscles. Intervention studies 
would be necessary to understand the adaptive power of different muscle groups and their role in gait performance in the elderly. Based on such studies the implications of the present work for clinical interventions can be tested.

\section{References}

[1] Judge J, Davis 3rd R, Ounpuu S. Step length reductions in advanced age: the role of ankle and hip kinetics. J Gerontol A: Biol Sci Med Sci 1996;51(6):M303-12.

[2] Winter DA, Patla AE, Frank JS, Walt SE. Biomechanical walking pattern changes in the fit and healthy elderly. Phys Ther 1990;70(6):340-7.

[3] Oberg T, Karsznia A, Oberg K. Basic gait parameters: reference data for normal subjects, 10-79 years of age. J Rehabil Res Dev 1993;30: 210-23.

[4] Kerrigan DC, Todd MK, Croce UD, Lipsitz LA, Collins JJ. Biomechanical gait alterations independent of speed in the healthy elderly: evidence for specific limiting impairments. Arch Phys Med Rehabil 1998;79(3):317-22.

[5] Prince F, Corriveau H, Hebert R, Winter DA. Gait in the elderly. Gait Posture 1997;5(2):128-35.

[6] Guimaraes RM, Isaacs B. Characteristics of the gait in old people who fall. Int Rehabil Med 1980;2(4):177-80.

[7] Wolfson L, Judge JO, Whipple R, King M. Strength is a major factor in balance, gait and the occurrence of falls. J Gerontol A: Biol Sci Med Sci 1995;50:64-7.

[8] Judge JO, Schechtman K, Cress E. The relationship between physical performance measures and independence in instrumental activities of daily living. The FICSIT group. Frailty and injury: cooperative studies of intervention trials. J Am Geriatr Soc 1996;44(11):1332-41.

[9] Daley MJ, Spinks WL. Exercise, mobility and aging. Sports Med 2000;29(1):1-12.

[10] Kerrigan DC, Todd MK, Della Croce U, Lipsitz LA, Collins JJ. Biomechanical gait alterations independent of speed in the healthy elderly: evidence for specific limiting impairments. Arch Physiol Med Rehabil 1998;79(3):317-22.

[11] DeVita P, Hortobagyi T. Age causes a redistribution of joint torques and powers during gait. J Appl Physiol 2000;88:1804-11.

[12] Hunter GR, McCarthy JP, Bamman MM. Effects of resistance training on older adults. Sports Med 2004;34(5):329-48.
[13] Tarpenning KM, Hamilton-Wessler M, Wiswell RA, Hawkins SA. Endurance training delays age of decline in leg strength and muscle morphology. Med Sci Sports Exerc 2004;36(1):74-8.

[14] Hunter GR, Treuth MS, Weinsier RL, Kekes-Szabo T, Kell SH, Roth DL, et al. The effect of strength conditioning on older women's ability to perform daily tasks. J Am Geriatr Soc 1995;43(7):756-60.

[15] Savelberg HHCM, Meijer K. Contribution of mono- and biarticular muscles to extending knee joint moments in runners and cyclists. $\mathrm{J}$ Appl Physiol 2003;94:2241-8.

[16] Savelberg HHCM, Meijer K. The effect of age and joint angle on the proportionality of extensor and flexor strength at the knee joint. $\mathrm{J}$ Gerontol A: Biol Sci Med Sci 2004;59A(11):1120-8.

[17] van Ingen Schenau GJ, Pratt CA, Macpherson JM. Differential use and control of mono- and biarticular muscles. Hum Movement Sci 1994; 14:495-517.

[18] Swanson SC, Caldwell GE. An integrated biomechanical analysis of high speed incline and level treadmill running. Med Sci Sports Exerc 2000;32(6):1146-55.

[19] Kyröläinen H, Pullinen T, Candau R, Avela J, Huttunen P, Komi PV. Effects of marathon running on running economy and kinematics. Eur J Appl Physiol 2000;82(4):297-304.

[20] Eng JJ, Winter DA. Kinetic analysis of the lower limbs during walking: what information can be gained from a three-dimensional model? J Biomech 1995;28(6):753-8.

[21] Prilutsky BI, Gregor RJ. Swing- and support-related muscle actions differentially trigger human walk-run and run-walk transitions. J Exp Biol 2001;204(13):2277-87.

[22] Robertson DGE, Caldwell GE, Hamill J, Kamen G, Whittlesey SN Research methods in biomechanics Champaign, Illinois: Human Kinetics; 2004.

[23] Karamanidis K, Arampatzis A. Mechanical and morphological properties of different muscle-tendon units in the lower extremity and running mechanics: effect of aging and physical activity. J Exp Biol 2005;208(20):3907-23.

[24] Voorrips LE, Ravelli CJ, Dongelmans PCA, Deurenberg P, Van Staveren WA. A physical activity questionnaire for the elderly. Med Sci Sports Exerc 1991;23:974-9.

[25] Hof AL. Scaling gait data to body size. Gait Posture 1996;4(3):222-3.

[26] Winter DA. Biomechanics and motor control of human movement New York: John Wiley \& Sons; 1990.

[27] Winter DA. Overall principle of lower limb support during stance phase of gait. J Biomech 1980;13:923-7. 